\title{
Percutaneous absorption of urea
}

\author{
CHRISITA ACKERMANN, GORDON L. FLYNN* and CHRIS J. VAN WYK, Department \\ of Pharmaceutics, Potchefstroom University for Christian Higher Education, Potchefstroom, \\ 2520, South Africa, ${ }^{*}$ College of Pharmacy, University of Michigan, Ann Arbor, Michigan, \\ 48109, USA
}

Presented at the XIII IFSCC Congress 16-19 October 1984 in Buenos Aires, Argentina

Key words: percutaneous absorption, urea, in vitro diffusion

\section{Synopsis}

The effect of several variables on the in vitro permeation of urea through hairless mouse skin has been studied in order to determine the causes of an increasing permeability phenomenon found in studies with a range of hydrophilic compounds.

The permeation of urea increased for a period of approximately $100 \mathrm{~h}$ after which a steady state permeation pattern was observed for approximately $25 \mathrm{~h}$. Urea did not effect its own permeation in concentrations between $0.01 \mathrm{M}$ and $1.67 \mathrm{M}$, and the same pattern of increasing permeation was followed in the presence of ( $N$-morpholine)propanesulphonic acid and tris(hydroxyme)amino-methane buffers, as in the presence of normal saline. Urea did not affect the permeation of tritiated water. Methanol and water exhibited the same pattern of increasing permeation as urea.

The continuously increasing permeation rate of urea up to $100 \mathrm{~h}$ is believed to be due to penetration and extensive association of water with the components of the stratum corneum, altering the ultra-structure of the stratum corneum and leading to the formation of large and extensive hydrophilic diffusion channels which do not exist in fresh, untreated skin. These presumed channels open the stratum corneum to facile permeation of highly polar substances such as urea. The physical events leading up to the ultra structural changes within the tissue at the microscopic level remain obscure and are the subject of ongoing research.

\section{L'absorption percutanée de l'urée}

\section{Résumé}

Dans le but d'expliquer la forte augmentation de la pénétration cutanée d'une série de composés hydrophiles, on a étudié les différents paramètres de la pénétration de l'urée sur la souris sans poils.

La pénétration de l'urée augmente sur une période d'une centaine d'h après quoi, une phase stationnaire a été observée pendant $25 \mathrm{~h}$ environ. Les pénétrations de l'urée ne sont pas modifićes pour des concentrations comprises entre $0.01 \mathrm{M}$ et $1.67 \mathrm{M}$, et le même type de pénétration est observé en présence de tampons biologiques tels que le ( $N$-morpholine)propane sulphonic acid et le tris(hydroxyme)amino-methane, comme en présence de sels. L'urée ne modifie pas la pénétration du tritium. Le méthanol et l'eau présentent la mème séquence d'augmentation de la pénétration que l'urée.

L'accroissement continuel du taux de pénétration de l'urée pendant $100 \mathrm{~h}$ est probablement dû à la pénétration et l'association extensive de l'eau avec les composants de la couche cornée. Ceci modifie la structure de la couche cornée par la création de larges canaux de diffusion hydrophiles qui n'existent pas sur la peau fraîche et non traitée. Ces présumés canaux facilitent la pénétration des substances très polaires telles que l'urée. On n'a pas encore expliqué les phénomènes physiques qui au niveau microscopique conduisent à ces changements de structure tissulaire et des recherches se poursuivent sur cette question. 


\section{INTRODUCTION}

Urea has been used as an active ingredient in many commercial preparations designed for normal or pathological skin (1), and is considered to be part of the natural moisturization factor in skin. Different effects of urea on the skin have been reported in the literature eg, an increase of the water binding capacity of the skin $(1,2)$; thinning of the epidermis $(3)$; keratolysis $(1)$; antibacterial and proteolytic activity (4).

Wahlberg and Swanbeck (5) found a very low permeability for the permeation of urea through human skin. Experiments on the penetration of urea through hairless white mini-pig skin were conducted in vivo by Wohlrab and Schiemann (6). It was found that urea penetrated the skin very rapidly and could be detected in the serum after a short while, but despite the rapid absorption, the total amount of urea absorbed was very small. These findings confirm the belief that the stratum corneum forms a very effective barrier against the penetration of urea.

However, while assessing the permeability coefficient of hydrophylic compounds in a previous study (7), an increase in permeability as a function of time was noted. Therefore, the main objective of this study was to systematically investigate different variables in order to explain the reason for this phenomenon. The increase in permeability may be affected by any one, or a combination of, the following aspects: the permeating substances (urea and normal saline) may alter the diffusion pathways in the skin mechanistically; extensive contact with the stirred bathing media may lead to physical deterioration of the skin, since water-soluble components may be washed out of the skin and still make it more susceptible to microbial attack. It has been reported in the literature that even hydration of the stratum corneum does not impair its barrier properties $(8,9)$. Therefore, physical deterioration and microbial attack were not primary concerns, especially because this increasing permeability was noticeable even during the first six $\mathbf{h}$ of an experiment. It was therefore decided to concentrate initially on the effects that the permeating substances might have on the permeation pattern.

Urea was chosen for conducting a more intensive study on the permeability patterns in relation to other parameters because reproducible results could be obtained with urea; the increase in permeability as a function of time was the most pronounced in the case of urea, and urea is used in many preparations for application to the skin, so that its effects on skin are interesting in their own right.

The following variables will be discussed: the time before steady state is reached; the influence of hydration by measuring permeation after different pre-hydration times and by doing sequential permeation studies on the same piece of skin; the influence of the isotonic bathing media by using normal saline, ( $N$-morpholine)propanesulphonic acid (MOPS) and tris(hydroxyme)amino-methane (TRIS) at a pH of approximately 5.5; the influence of the concentration of the permeating compound by using three different concentrations; the effect of urea on the permeation of water and methanol by means of a dual label experiment; the effect of stripping on the permeation of urea.

All the permeation studies were done in vitro with hairless mouse skin by means of a diffusion cell system.

\section{MATERIALS AND METHODS}

\section{Animals}

The abdominal skin of male hairless mice (from genetic background BALB/c $\times$ HA/Icr, Dairy Research Council, Irene, South Africa) were used. The mice were at least 90 days old and 
weighed $\pm 24 \mathrm{~g}$. The mice were killed by severing the spinal cord. Four abdominal sections of full thickness skin, each about $1.5 \mathrm{~cm}^{2}$ in area were removed from the mouse by blunt dissection and mounted between the cells of four glass diffusion cell systems.

\section{Chemicals}

${ }^{14} \mathrm{C}$-Urea (New England Nuclear, Boston, USA) was used in a concentration of $3.7 \times 10^{-5} \mathrm{M}$. Unlabelled reagent grade urea (Mollincrodt, St. Louis, USA) in a concentration of $0.01 \mathrm{~m}$ was used on both sides of the membrane to saturate the sorptive capacity of the cell system, so that the permeation of the tracer amount of labelled urea could easily be followed. All solutions were made isotonic by using normal saline and water (sterile pyrogenfree, for intravenous use, Labethica, Bethlehem, South Africa).

\section{Procedures}

\section{General Procedures}

The diffusion cell system consisted of two glass cells with a volume of approximately $1.3 \mathrm{ml}$ each. When the skin was mounted (clamped) between the cells an area of $0.7128 \mathrm{~cm}^{2}$ of skin was exposed to the contents of the cells. The contents of each cell were stirred by a small propellertype stirrer (Model CA115V, Hurst Manufacturing, Indiana, USA) which maintained the stirring speed at 150 r.p.m. The diffusion cell system was mounted in a water-bath in which the temperature was maintained at $37 \pm 1^{\circ} \mathrm{C}$.

The cell into which the high concentration of compound was inserted was called the donor cell, and the other cell, in which the concentration was kept as low as possible, was called the receiver cell. The essentials of a sink condition were maintained throughout each experiment, which means that the receiver cell should contain an infinitely small concentration of the diffusing compound in comparison to the concentration within the donor cell. The limit was taken that the receiver cell should not contain a higher concentration than $5 \%$ of the donor cell concentration of radio-labelled compound. This means that the thermodynamic driving force was not allowed to drop to below $90 \%$ of the original level. After each piece of skin was excised and clamped between the two cells, the cell system was put into the water-bath and $1.2 \mathrm{ml}$ of a normal saline solution (pre-warmed to $37^{\circ} \mathrm{C}$ ) was put into each cell.

After all four cell systems were put into the water-bath, the stirrers were connected to the motors. The skin was bathed in this manner for $0.5-1.0 \mathrm{~h}$ before the experiment commenced.

When it became necessary to exchange the medium in either cell, the contents of the cells were removed by means of a syringe with a piece of plastic tubing connected to the needle for easier evacuation of the cell. In all experiments a standard volume of $1.2 \mathrm{ml}$ was put in each cell. Samples of $20 \mu \mathrm{l}$ and $400 \mu \mathrm{l}$ respectively were taken from the donor and receiver cells at specified time intervals and replenished accordingly. The samples were put in $10 \mathrm{ml}$ of a scintillation cocktail (Aquasol, New England Nuclear, Massachussets, USA) before being analysed in a scintillation counter (Model LS 9000 liquid scintillation counter, Beckman Instruments, California, USA). Between manipulations the sample-taking ports were closed by means of micropipette tips which wcre wrapped in Parafilm before using them as stoppers for the ports.

Assessment of the time to reach steady state

$\left({ }^{14} \mathrm{C}\right)$-Urea (New England Nuclear, Boston, USA) in a concentration of $3.7 \times 10^{-5} \mathrm{M}$ was used. An isotonic solution of $0.01 \mathrm{M}$ unlabelled urea in normal saline was placed in both donor and 
receiver cells. A long continuous experiment was executed and the cell contents were completely replaced every $8 \mathrm{~h}$. Donor cell samples were only taken immediately before and after replacement of donor cell contents. Receiver cell samples were taken at intervals of $2-4 \mathrm{~h}$ except overnight, when only one receiver sample was taken in the morning before the replacement of the contents of both cells.

\section{Influence of hydration}

The skin was hydrated with a normal saline solution. A labelled urea solution of $3.7 \times 10^{-5} \mathrm{M}$ was monitored as the permeating substance. During the permeation studies both the donor and receiver cells contained $0.01 \mathrm{~m}$ unlabelled urea. Four pieces of skin were hydrated simultaneously for $24,48,72$ and $96 \mathrm{~h}$ respectively before the permeation experiment commenced.

\section{Sequential run procedure}

Seven separate diffusion runs were done over a period of $128 \mathrm{~h}$ on the same mouse skin. Between runs the skin was rinsed and soaked with normal saline. Each run was done with a $3.7 \times 10^{-5} \mathrm{M}$ solution of ${ }^{14} \mathrm{C}$-urea. A $0.01 \mathrm{M}$ urea solution in saline was used as the diffusional medium. After each run the contents of both diffusion cells were removed and both cells were rinsed five times with normal saline. Each cell was then filled with $1.2 \mathrm{ml}$ normal saline and left for approximately $12 \mathrm{~h}$. Each cell was rinsed another five times before the next run commenced. Control samples of the rinsing and soaking solutions after different time intervals showed that this procedure was efficient in eliminating labelled urea from the previous run in each case. The saline rinses contained no urea, and no urea was present between permeation experiments.

\section{Different concentrations of urea}

The three concentrations used were $0.01 \mathrm{M}, 0.27 \mathrm{M}$ (maximum concentration of urea that is still isotonic) and $1.67 \mathrm{M}$ (the equivalent of $10 \% \mathrm{w} / \mathrm{v}$ urea which is used in many percutaneous absorption studies).

The different concentrations were made up of labelled and unlabelled urea. Each contained the same amount of labelled urea $\left(3.7 \times 10^{-5} \mathrm{M}\right)$ with unlabelled urea added to obtain the desired concentration in the donor cell. The receiver cell contained a $0.01 \mathrm{M}$ solution of unlabelled urea.

\section{Permeation of urea in the presence of different isotonic media}

MOPS and TRIS, which are both well known biological buffers, were chosen to compare to the normal saline as a bathing medium. MOPS and TRIS were used in a concentration of $0.5 \mathrm{M}$. The $\mathrm{pH}$ of the solutions was adjusted to $5.5 \pm 0.2$ by the addition of $1 \mathrm{M} \mathrm{NaOH}$ and $1 \mathrm{M} \mathrm{HCl}$, respectively. Urea was used in a concentration of $0.27 \mathrm{M}$.

Simultaneous permeation of ${ }^{14} \mathrm{C}$-urea with ${ }^{3} \mathrm{H}$-water and ${ }^{14} \mathrm{C}$-methanol with ${ }^{3} \mathrm{H}$-water The following concentrations were used: $3.7 \times 10^{-5} \mathrm{M}{ }^{14} \mathrm{C}$-urea, $5.6 \times 10^{-5} \mathrm{M}^{3} \mathrm{H}$-water and $7.5 \times 10^{-4} \mathrm{M}^{14} \mathrm{C}$-methanol. Samples were taken every hour from the receiver cell for four $h$ and samples from the donor cell were taken before and after each 4-h run. These 4-h runs were repeated at $24,48,72,96$ and $144 \mathrm{~h}$. 
Permeation of urea through stripped skin

The hairless mouse skin was stripped by means of Scotch Magic Tape (1R No 810, 3M South Africa (Pty) Ltd). The donor cell contained $0.01 \mathrm{M}$ unlabelled urea and $3.7 \times 10^{-5} \mathrm{M}{ }^{14} \mathrm{C}$-urea and the receiver cell contained $0.01 \mathrm{M}$ unlabelled urea. Both solutions were made isotonic with normal saline.

\section{RESULTS AND DISCUSSION}

Each data point in the figures is the mean of four determinations.

\section{Time to reach steady state}

When the permeability coefficients are observed as a function of time for the in vitro permeation of urea through full thickness hairless mouse skin, a rapid increase in permeation persisted until approximately $100 \mathrm{~h}$, after which the rate stayed constant for at least $24 \mathrm{~h}$ (Fig. 1). This is in contrast to the results that other workers obtained for the percutaneous absorption of other hydrophilic compounds like water, mcthanol and ethanol $(10,11)$ where a steady state was reached within an hour after the experiment started.

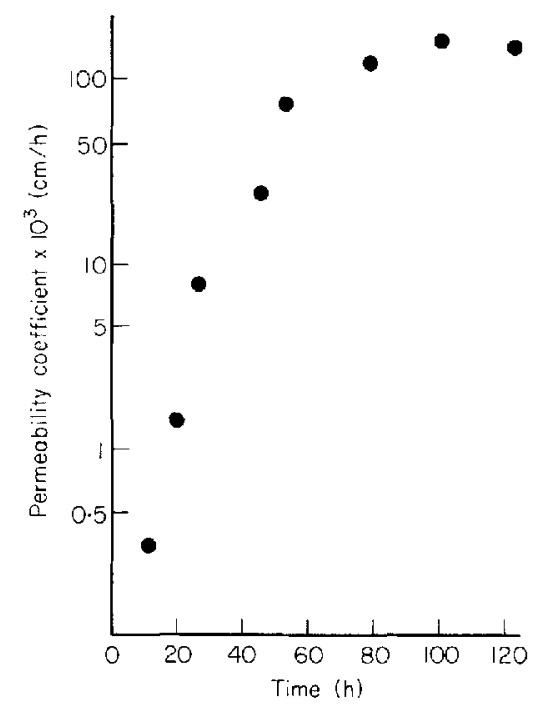

Figure 1. The permeability coefficients of a $0.01 \mathrm{M}$ urea solution as a function of time.

In this permeation study with urea the epidermal barrier had apparently undergone changes in the diffusion process with time. It was not known whether this was due to the influence of the permeating substance or whether an hydration effect had been observed. The term 'hydration' should only be applied to instances where water is bound by components of the skin, and particularly the stratum corneum. It will be assumed that hydration does not cause any physical changes of the skin strata involved.

\section{Effect of hydration}

According to hydration studies done by other workers (9), hydration was not expected to have a large influence over the first $12-24 \mathrm{~h}$. The plateau phase was reached in $96 \mathrm{~h}$ in the previous experiments. It was therefore decided to hydrate the skin for different time intervals up to $96 \mathrm{~h}$ 
before initiating a permeation experiment. The objective was to discriminate between the hydration effect and the effect that urea might have had on the skin during permeation.

No significant difference in the permeability pattern was found for the four different hydration times (Fig. 2). This result indicates that urea did not induce an increase in its own permeability in the concentration used in this experiment. It has to be noted that a $0.01 \mathrm{M}$ of unlabelled urea solution was used on both sides of the membrane during a permeation experiment.

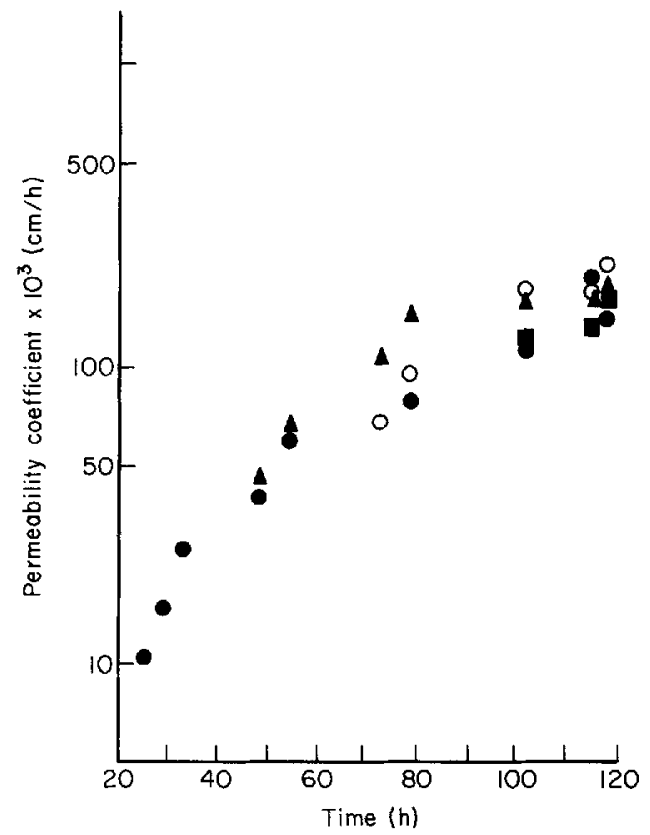

Figure 2. The permeability coefficients of a $0.01 \mathrm{~m}$ solution of urea as a function of time after full thickness hairless mouse skin has been hydrated for $24 \mathrm{~h}(\bullet), 48 \mathrm{~h}(\Delta), 72 \mathrm{~h}(0)$ and $96 \mathrm{~h}(\square)$. Four pieces of skin from the same mouse were used.

The objective with the sequential run procedure was to do an experiment comparable with those done by other workers (9) as a control of the effect of hydration. The relevant data on the permeability of urea with the sequential run procedure are shown in Figure 3. Each run is represented by two points. The first point is the mean permeability over the first $4 \mathrm{~h}$ of each run and the second point is the mean permeability over the last $4 \mathrm{~h}$ of each run.

Although urea was not continuously in contact with the skin during the sequential run procedure, the same pattern of increasing permeability was found as with the continuous experiments (Fig. 1). As with the previous experiment the results show that it is not the prolonged contact of urea with the skin that alters the permeability of the barrier, but some other common factor present in both the continuous and sequential run procedures. A normal saline solution was continuously in contact with the skin in both procedures. This suggests that hydration may be the cause of the increasing permeability. Other workers (9) did not observe such a dramatic effect of hydration with the permeation of a series of alkanols over a permeation period of $30 \mathrm{~h}$. This might be an indication that the hydration factor particularly affects the barrier for urea permeation, but not that of semi-polar alkanols, or that the effect of hydration was not so 


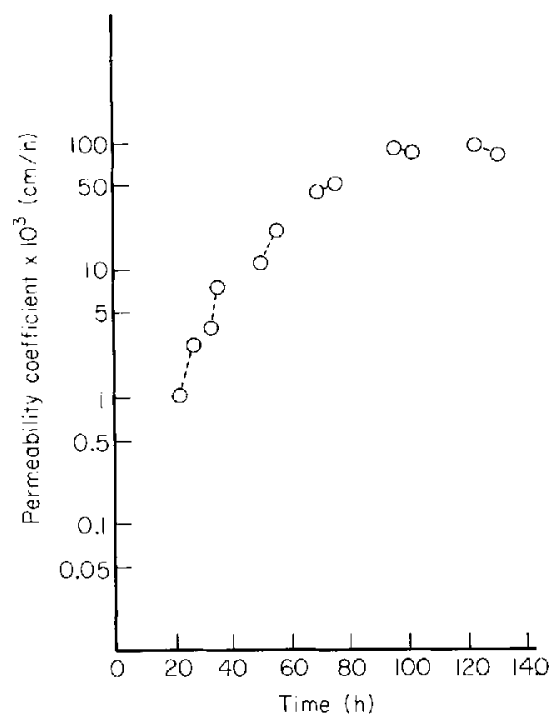

Figure 3. The permeability coefficient of a $0.01 \mathrm{~m}$ urea solution as a function of time when the sequential run procedure is followed. Each $\left(\mathrm{O}_{-} \mathrm{O}^{\circ}\right.$ ) represents the mean permeability coefficient of the first $4 \mathrm{~h}$ and the last $4 \mathrm{~h}$ of each sequential rum.

acutely visible over a time span of $30 \mathrm{~h}$. It might also be that urea has a measurable effect on its own permeation, in which case one would expect this effect to increase with an increase in the concentration of urea in contact with the skin.

\section{Differ: nt concentrations of urea}

The relevant data on the permeability of different concentrations of urea are shown in Figure 4. When the experimental variation is taken into account, the same quantitative and qualitative permeation pattern is seen with all three concentrations of urea, although the highest concentration differed from the lowest concentration by two logarithmic orders of magnitude. The increasing permeability pattern definitely does not depend upon the concentration of the permeating urea in the concentration range of $0.01 \mathrm{M}$ to $1.67 \mathrm{M}$.

\section{Different isotonic bathing media}

The only other compound except water that might influence the permeability barrier is the sodium chloride used to render the bathing medium isotonic. Comparing the effect of different isotonic bathing media on the permeation of urea through full thickness hairless mouse skin should give an indication of the effect of sodium chloride on the permeability barrier. The relevant data on the permeation of urea in the presence of different isotonic media are shown in Figure 5.

When the experimental variation is taken into account, the permeation of urea in the presence of MOPS and TRIS buffers follows the same pattern of increasing permeation as in the presence of normal saline. The permeability coefficient at $70-78 \mathrm{~h}$ differed quantitatively for the three isotonic media, and although the limited data prohibit a definite conclusion, it seems as if the permeation of urea in the presence of MOPS and TRIS is a little slower in the steady state 


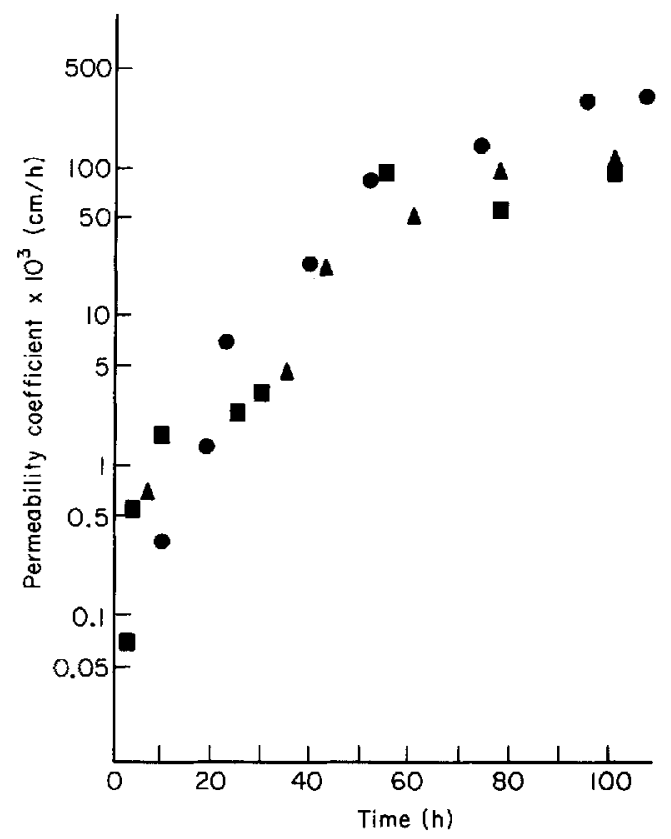

Figure 4. The permeability coefficients of different concentrations of urea as a function of time: $0.01 \mathrm{M}(\bullet)$; $0.27 \mathrm{M}(\mathbf{\Delta}) ; 1.67 \mathrm{M}(\boldsymbol{\nabla})$.

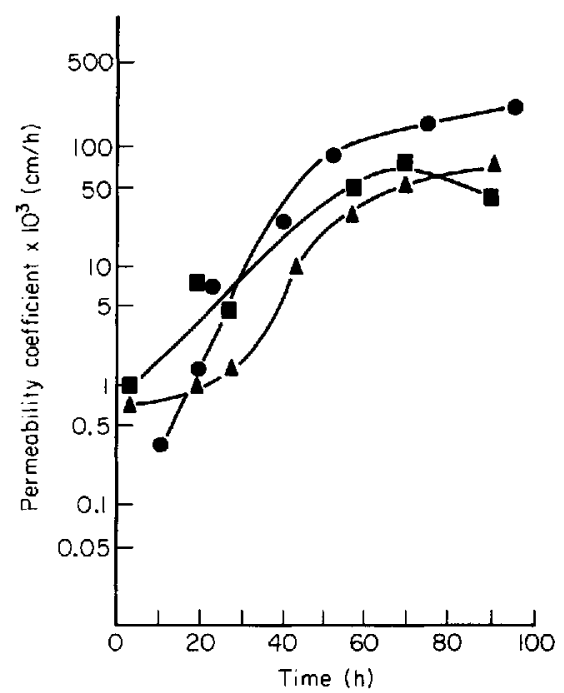

Figure 5. The permeability coefficients of a $0.01 \mathrm{~m}$ solution of urea in different isotonic media as a function of time: normal saline $(\bullet)$; MOPS $(\mathbf{\Delta})$; TRIS $(\boldsymbol{\bullet})$. 
phase that is the case in the presence of normal saline. This small variation may also be ascribed to mouse-to-mouse variation.

\section{Comparison of the permeation of urea, water and methanol}

The permeability pattern of urea as found in this study differs very much from that of the reported pattern of other hydrophilic compounds like water, methanol and ethanol. In the studies with water, methanol and ethanol the increase in permeability as a function of time over such a prolonged period was not observed and the steady state phase was attained within $1 \mathrm{~h}$. If these differences are associated in some way with the heterogeneous nature of the stratum corneum, it would be expected that in a dual-label experiment where ${ }^{14} \mathrm{C}$-urea and ${ }^{3} \mathrm{H}$-water are permeated simultaneously, that urea will show the increasing permeability pattern, while the permeability of water will not change as a function of time. Figure 6 displays the relevant data on the simultaneous permeation of ${ }^{14} \mathrm{C}$-urea and ${ }^{3} \mathrm{H}$-water. The water and the urea exhibit the same pattern of rapid increase in permeability over $150 \mathrm{~h}$. There is no significant difference, therefore, between the effect of the barriers to the permeation of these compounds. In fact, it seems to be the same barrier operating for both compounds.

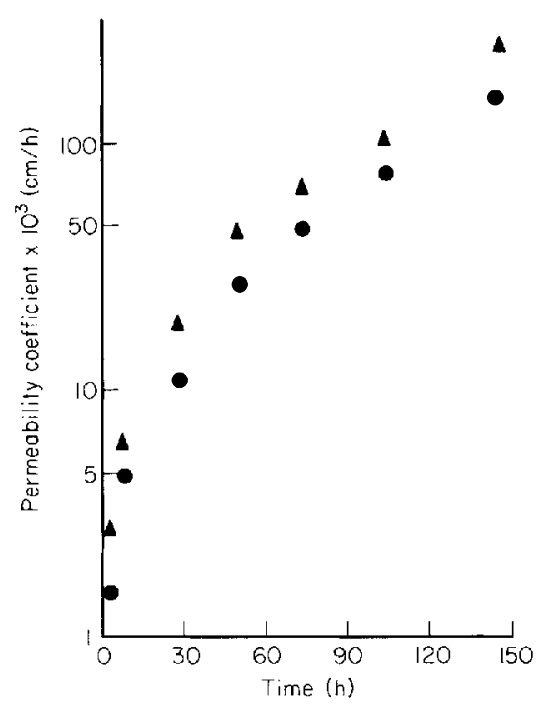

Figure 6. The permeability coefficient of a $0.01 \mathrm{M}$ urea $(\bullet)$ and a $5.6 \times 10^{-5} \mathrm{M}^{3} \mathrm{ll}$-water solution ( $\boldsymbol{A}$ ) for full thickness hairless mouse skin as a function of time.

According to Behl et al., (9) the permeabilities of the hydrophilic solutes, water, methanol and ethanol were not changed by hydration when using hairless mouse skin (SKH-hr ${ }^{1}$ strain). In contrast to the hairless mouse skin results, Behl et al. (9) found that hydration studies with the Swiss mouse revealed hydration effects on the permeability of water. methanol and ethanol. The permeability of water increased up to $30 \mathrm{~h}$ of hydration and showed signs of levelling off between 30 and $43 \mathrm{~h}$. The hydration profile differences between the Swiss mouse and the hairless mouse were apparently due to the abundant follicular presence in the Swiss species. Qualitatively the same permeation profile was found for urea with the SKH-hr ${ }^{-1}$ hairless mouse skin 
and the South African counterpart (nude mutant gene from genetic background BALB/c $\times$ HA/lcr) (7). Although the latter also has an abundance of follicles, with both species an increase in permeation as a function of time was observed. From this observation it can be concluded that the hair follicles are not the major determinant of the accelerated permeation.

Since the stratum corneum is generally accepted as the major barrier to the permeation of hydrophilic compounds $(8,10,12)$, the increase in permeation must be a function of changes in the stratum corneum. The question is whether these changes have the same effect on the permeation of all hydrophilic compounds. From the results found when water and urea were permeated simultaneously, it seemed as if the changes in the stratum corneum affected the permeation of water and urea in the same way. This study was conducted to test the hypothesis that the mechanism of permeation of urea and methanoldiffers. Unfortunately, while ${ }^{14} \mathrm{C}$-methanol was available at the time of the study, ${ }^{3} \mathrm{H}$-methanol was not. Therefore, a simultaneous run of ${ }^{14} \mathrm{C}$ methanol and ${ }^{3} \mathrm{H}$-water was to be compared to the simultaneous run of ${ }^{14} \mathrm{C}$-urea and ${ }^{3} \mathrm{H}$-water. Figure 7 displays the relevant data on the simultaneous permeation of ${ }^{14} \mathrm{C}$-methanol and ${ }^{3} \mathrm{H}$-water.

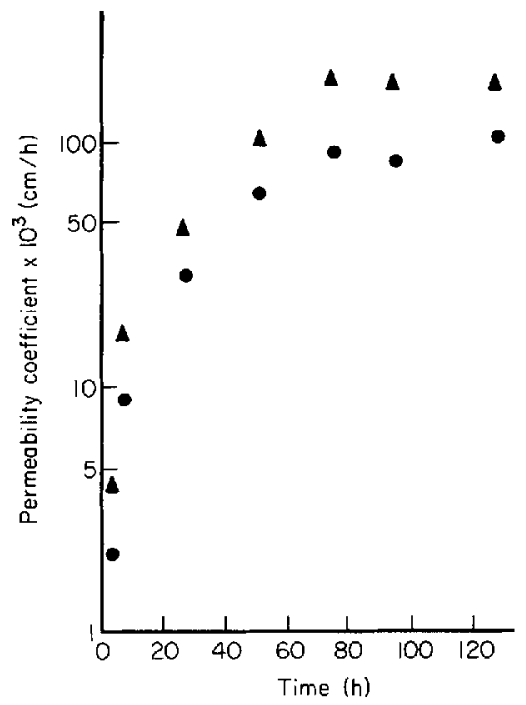

Figure 7. The permeability of a $7.5 \times 10^{-4} \mathrm{M}{ }^{14} \mathrm{C}-$ methanol $(\bullet)$ and a $5.6 \times 10^{-5} \mathrm{M}{ }^{3} \mathrm{H}$-water solution $(\Delta)$ as a function of time for full thickness hairless mouse skin.

The simultaneous permeation of methanol and water also exhibits a pattern of increasing permeation, which correlates very well with the trend observed when urea and water permeated simultaneously. The results obtained when urea and water permeated simultaneously exhibit a slight quantitative difference from those obtained with methanol and water. But when experimental variation is taken into account, the difference cannot be ascribed to mechanistic differences. No significant difference in the mechanism of and the barrier to the permeation of urea, methanol and water could be found.

\section{Permeation of urea through stripped skin}

Although the stratum corneum is generally accepted as the main barrier to the permeation of substances through skin, it is also well known that hydration of the stratum corneum leads to an 
increase in permeability (13). When the stratum becomes so much hydrated that it offers no significant barrier to the permeation of very hydrophilic compounds, the remainder of the epidermis might become the major barrier to the permeation of hydrophilic compounds through excessively hydrated skin. By stripping full thickness skin to different degrees and conducting exactly the same experiment on the different pieces of stripped skin, a qualitative estimation of the relative contributions of other cell layers to the barrier properties should be possible. Figure 8 displays the relevant data on the permeation of ${ }^{14} \mathrm{C}$-urea through stripped skin. For up to $20 \mathrm{~h}$, the full thickness hairless mouse skin showed the lowest permeability, followed by the $\times 10$ stripped and $\times 20$ stripped skin, respectively. This phenomenon is expected when the stratum corncum forms the main barrier to permeation. The highest permeability which is observed initially with the $\times 10$ and $\times 20$ stripped skin could be ascribed to the decrease in the thickness of the horny layer. An unexpected observation is that the permeation through full thickness skin seems to increase much faster than permeation through the $\times 10$ stripped skin, so much so that after approximately $40 \mathrm{~h}$ the permeability coefficient of urea permeating full thickness skin is significantly higher than those of urea permeating the $\times 10$ stripped skin.

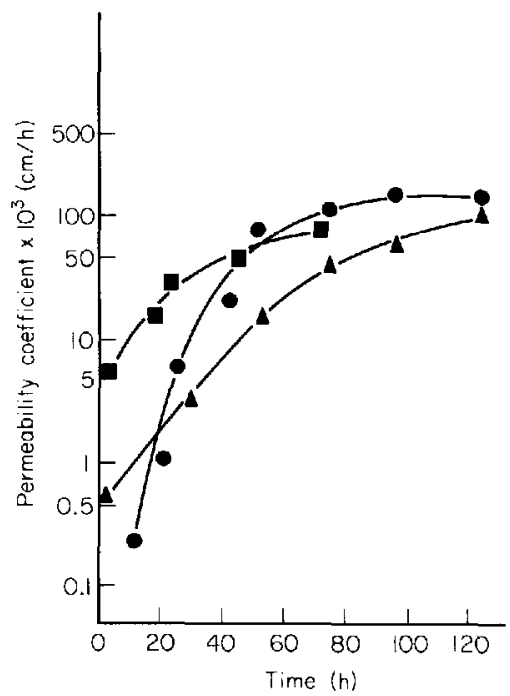

Figure 8. The permeability coefficient as a function of time for the permeation of a $0.01 \mathrm{~m}$ urea solution through full thickness hairless mouse skin $(\bullet)$, skin that has been stripped $\times 10(\Delta)$ and $\times 20(0)$.

Stripping is incomplete, but removes the most heavily bacteria-contaminated layers. Therefore micro-organisms might be more abundantly present on the full thickness skin than on the stripped skin. The outer loose, more 'hydrophilic' cells of the full thickness stratum corneum might form a better growth medium for micro-organisms than the lipophilic surface of the stripped skin during extensive hydration, as found during the experiments in this study.

\section{CONCLUSIONS}

The effect of several variables on the permeation of urea through hairless mouse skin has been studied in order to determine the causes of the increasing permeability phenomenon found in the preliminary studies. It was found that the permeation of urea increased for a period of 
approximately $100 \mathrm{~h}$, after which a steady-state permeation pattern was observed for approximately $25 \mathrm{~h}$. A mass balance between the donor and receiver sides of the membrane was reached within a much shorter time: due to the very low permeability of urea in the first few hours of the experiment and the experimental variation, this period can only be estimated as between $1 \mathrm{~h}$ and $4 \mathrm{~h}$. Thus a very short 'lag time' and mass balance is seen even during the increasing permeability phase.

Hydration was thought to be one of the possible causes of the increasing permeability phenomenon. In two experiments, one where the skin was hydrated for different time intervals before starting a permeation experiment, and the other where a sequential run procedure was utilized, it was found that hydration, or the effect of the bathing medium on the skin, was the major cause for the increasing permeation. Urea was found not to affect its own permeation in a concentration of $0.01 \mathrm{M}$. The question arose as to whether urea would effect its own permeation in higher concentrations than $0.01 \mathrm{M}$. After permeation studies with $0.27 \mathrm{M}$ and $1.67 \mathrm{M}$ it could be concluded that there was no signficant difference between the permeation of urea in those concentrations that differed by two logarithmic orders. This result confirmed that the permeating urea was not the cause of the increasing permeability.

It seemed that the only alternative cause for the increasing permeability would be found in the isotonic bathing media. Two other isotonic media, MOPS and TRIS, were used with a 0.27 $M$ solution of urea, and the results were compared to that obtained with the normal saline bathing media. When the experimental variation was taken into account, the permeation of urea in the presence of the MOPS and TRIS buffers followed the same pattern of increasing permeation as in the presence of normal saline.

Although it was found that contact with the isotonic bathing media was the primary cause of the increasing permeation, none of the above-mentioned studies explicitly indicated a hydration or other mechanistic effect. Therefore, it was decided to compare the permeation of urea with that of other hydrophilic compounds for which an increasing permeability was not observed previously. In studies with water, methanol and ethanol $(10,11)$ the increase in permeability as a function of time over such a prolonged period was not observed, and the steady state phase was attained within $1 \mathrm{~h}$. If the difference between these compounds and urea are associated in some way with the heterogeneous nature of the stratum corneum, implying different permeation mechanisms for example for urea and water, it could be expected that in a dual label experiment where ${ }^{14} \mathrm{C}$-urea and ${ }^{3} \mathrm{H}$-water are permeated simultaneously that urea will show the increasing permeability pattern, while the permeability of water will not change as a function of time. This hypothesis was tested by conducting simultaneous runs of ${ }^{14} \mathrm{C}$-urea, ${ }^{3} \mathrm{H}$-water and ${ }^{14} \mathrm{C}$ methanol. When the permeation patterns over the first $6 \mathrm{~h}$ of these experiments were compared, it was clear that urea, methanol and water exhibit the same increasing permeability pattern. It was concluded, therefore, that no significant difference in the mechanism of and the barrier to the permeation of urea, methanol and water existed.

Whilst the stratum corneum is generally accepted as the main barrier to the penetration of substances through skin, it is also well known that hydration of the stratum corneum leads to an increase in permeability, although not to the extent seen in this study. When the stratum corneum becomes so much hydrated that it offers no significant barrier to the permeation of very hydrophilic compounds, the remainder of the epidermis might become the major barrier to the permeation of these compounds. From the results when urea permeated stripped skin, it was unexpectedly found that the permeation through full thickness skin increased much faster than permeation through $\times 10$ stripped skin. The only apparently viable conclusion was that although 
stripping is incomplete, it may have removed the most heavily bacteria-contaminated layers which reduced microbial attack on the permeation barrier, and thus slowed down any deteriorating effect the micro-organisms might have had on the permeation barrier.

Although the cause of the increasing permeation of urea could not be identified explicitly, a base for the solving of this problem has been developed and several important observations on the permeation of urea and the behaviour of hairless mouse skin in an in vitro diffusion system have been made, of which the following should be mentioned:

urea did not affect its own permeability, nor that of water. The increasing permeability could therefore not be ascribed to the permeating urea;

urea, methanol and water exhibited the same pattern of increasing permeability, contrary to what had been expected from other studies with methanol and water. The mechanism of permeation seemed to be the same for these compounds, and it appeared that it was not the permeating substance that was responsible for the increasing permeability, but another factor, common to all the experiments;

it seems, therefore, to be safe to conclude that the increasing permeability phenomenon was caused by the effect of the bathing medium on the skin. However, this effect may include various factors such as hydration, physical deterioration and provision of a growth medium for microbial proliferation: factors that should be studied more intensively in future studies.

\section{SUMMARY}

The effect of several variables on the permeation of urea through hairless mouse skin has been studied in order to determine the causes of an increasing permeability phenomenon found in preliminary studies. An infinite dose in vitro diffusion cell system was used. The following results were obtained:

a rapid increase in permeation persisted until approximately $100 \mathrm{~h}$, after which the rate stayed constant for at least $24 \mathrm{~h}$;

the bathing medium had a deteriorating effect on the permeation barrier;

between concentrations of $0.01 \mathrm{M}$ and $1.67 \mathrm{M}$ urea did not affect its own permeation significantly;

urea did not affect the permeation of water or methanol significantly, and

the barrier of $\times 10$ stripped skin is less susceptible to deterioration after $40 \mathrm{~h}$ of being in the diffusion medium than full thickness hairless mouse skin.

Although the cause of the increasing permeation of urea could not be explicitly identified, several important observations on the permeation of urea and the behaviour of hairless mouse skin in an in vitro diffusion system have been made, of which the following should be mentioned:

urea did not affect its own permeability nor that of water. The increasing permeability could therefore not be ascribed to the permeating urea;

urea, methanol and water exhibited the same pattern of increasing permeability, contrary to what had been expected from other studies with methanol and water. The mechanism of permeation seemed to be the same for these compounds, and it was not the permeating substance that was responsible for the increasing permeability, but another factor, common to all the experiments; 
it can be concluded that the increasing permeability phenomenon was caused by the effect of the bathing medium on the skin. However, this effect may include various factors such as hydration, physical deterioration and provision of a growth medium for microbial proliferation: factors that should be studied more intensively in future studies.

\section{ACKNOWLEDGEMENTS}

Financial assistance from the following bodies made this research possible: CSIR, Kernkor, Smith and Nephew through the Foundation for Pharmacy Education, Noristan, Smith, Kline \& Frensch, The Institute for Industrial Pharmacy and the Department of Pharmaceutics at the Potchefstroom University, South Africa.

\section{REFERENCES}

1. Hellgren, L. and Larsson, K. On the effect of urea on human epidermis. Dermatologica 149 289-293 (1974).

2. Grice, K., Sattar, H. and Baker, H. Urea and retinoic acid in ichthyosis and their effect on transepidermal water loss and water holding capacity of stratum corneum. Acta Dermato-venereol 53 114-118 (1973).

3. Wohlrab, von $W$. Zum Normalisierungsprozess in der Epidermis nach vorausgeganenem Harnstoffkontakt. Dermatol. Monatschrift 162 585-591 (1976).

4. Ashton, H., Frenk, E. and Stevenson, C. J. Urea as a topical agent. Br. J. Derm. 84 194-196 (1971).

5. Wahlberg, J. E. and Swanbeck, G. The effect of urea and lactic acid on the percutaneous absorption of hydrocortisone. Acta Dermato-venereol 53 207-210 (1973).

6. Wohlrab, von W. and Schiemann, S. Untersuchungen zum Mechanismus der Harnstoffwirkung auf die Haut. Arch. Dermatol. Forsch. 225 23-30 (1976).

7. Ackermann, C. Percutaneous absorption of hydrophilic compounds - an in vitro study on hairless mouse skin. D.Sc. thesis, Potchefstroom University for Christian Higher Education, South Africa (1983).

8. Scheuplein, R. J. and Blank I. H. Permeability of the skin. Physiol. Rev. 51 702-747 (1971).

9. Behl, C. R., Flynn, G. L., Kurihara, T., Harper, N., Smith, W. M., Higuchi, W. I., Ho, N. F. H. and Pierson, C. L. Hydration and percutaneous absorption: I. Influence of hydration on alkanol permeation through hairless mouse skin. J. Invest. Derm. 75 346-352 (1980).

10. Treherne, J. E. The permeability of skin to some non-electrolytes. J. Physiol. 133 171-180 (1956).

11. Dürrheim, H. H., Flynn, G. L., Higuchi, W. I. and Behl, C. H. Permeation of hairless mouse skin. I: Experimental methods and comparison with human epidermal permeation of alkanols. J. Pharm. Sci. 69 781-786 (1980).

12. Wohlrab, von W. and Hassler, N. Penetrationskinetik von Harnstoff in die menschliche Haut. Dermatol. Monatschrift 167 277-283 (1981).

13. Idson, B. Percutaneous absorption. J. Pharm. Sci. 64 901-924 (1975). 